\title{
Geographic and topographic determinants of local FMD transmission applied to the 200 I UK FMD epidemic
} Paul R Bessell*1, Darren J Shaw ${ }^{2}$, Nicholas J Savill ${ }^{1}$ and Mark EJ Woolhouse ${ }^{1}$

Address: ${ }^{1}$ Centre for Infectious Diseases, School of Biological Sciences, University of Edinburgh, Kings Buildings, West Mains Road, Edinburgh, EH9 3JT, UK and ${ }^{2}$ Veterinary Clinical Sciences, R(D)SVS, University of Edinburgh, Easter Bush Veterinary Centre, Roslin, Midlothian, EH25 9RG, UK

Email: Paul R Bessell* - p.r.bessell@sms.ed.ac.uk; Darren J Shaw - darren.shaw@ed.ac.uk; Nicholas J Savill - nick.savill@ed.ac.uk; Mark EJ Woolhouse - mark.woolhouse@ed.ac.uk

* Corresponding author

Published: 3 October 2008

BMC Veterinary Research 2008, 4:40 doi:10.1/86/1746-6/48-4-40

This article is available from: http://www.biomedcentral.com/I746-6/48/4/40

(C) 2008 Bessell et al; licensee BioMed Central Ltd.

This is an Open Access article distributed under the terms of the Creative Commons Attribution License (http://creativecommons.org/licenses/by/2.0), which permits unrestricted use, distribution, and reproduction in any medium, provided the original work is properly cited.
Received: 17 August 2007

Accepted: 3 October 2008

\begin{abstract}
Background: Models of Foot and Mouth Disease (FMD) transmission have assumed a homogeneous landscape across which Euclidean distance is a suitable measure of the spatial dependency of transmission. This paper investigated features of the landscape and their impact on transmission during the period of predominantly local spread which followed the implementation of the national movement ban during the 200 I UK FMD epidemic. In this study I I 3 farms diagnosed with FMD which had a known source of infection within $3 \mathrm{~km}$ (cases) were matched to 188 control farms which were either uninfected or infected at a later timepoint. Cases were matched to controls by Euclidean distance to the source of infection and farm size. Intervening geographical features and connectivity between the source of infection and case and controls were compared.

Results: Road distance between holdings, access to holdings, presence of forest, elevation change between holdings and the presence of intervening roads had no impact on the risk of local FMD transmission ( $p>0.2$ ). However the presence of linear features in the form of rivers and railways acted as barriers to FMD transmission (odds ratio $=0.507,95 \% \mathrm{Cls}=0.297,0.887, \mathrm{p}=0.018$ ).

Conclusion: This paper demonstrated that although FMD spread can generally be modelled using Euclidean distance and numbers of animals on susceptible holdings, the presence of rivers and railways has an additional protective effect reducing the probability of transmission between holdings.
\end{abstract}

\section{Background}

Foot and Mouth Disease (FMD) is a highly infectious viral disease of cloven hoofed animals. The outbreak that occurred in the UK between February and September 2001 resulted in 2026 Infected Premises (IPs) on the British mainland. An estimated 4.2 million animals were slaughtered for disease control purposes and another 2.5 million for welfare purposes [1]. The estimated direct and indirect costs of the epidemic were $£ 6$ billion [2].

The FMD virus can be transmitted through a variety of routes including aerosol transmission, direct contact between animals and on fomites, furthermore, the virus has been shown to spread over distances greater than 100 
$\mathrm{km}$ by viral plumes [3]. During the early stages of the 2001 UK epidemic long range transmission events were facilitated by the movements of infected animals; this was largely brought to an end by the imposition of the national movement ban (NMB) on susceptible animals introduced on the 23rd February. From this date, disease transmission was more localised with over $50 \%$ of transmission events occurring across distances of less than 3 $\mathrm{km}$ and more than $80 \%$ over distances of less than $10 \mathrm{~km}$ [4-6]. Some mathematical models of FMD transmission [6-8] incorporate this distance decay effect in the form of a kernel which describes the declining probability of infection with distance from an infectious source. This kernel assumes that the landscape is homogeneous and that elements of the landscape such as roads, rivers and topography have no influence on the likelihood of virus transmission. Furthermore, the kernel assumes that the distance between two holdings can be adequately modelled as straight line Euclidean distance rather than road distance or topographically adjusted Euclidean distance.

Savill et al [9] tested the utility of Euclidean distance compared to road distance between holding pairs at a coarse scale. The authors calculated Euclidean distances and road distances between an IP and a potential 'daughter IP' and between IPs and susceptible non-IPs over distances of up to $10 \mathrm{~km}$. They found no statistically significant difference in the correlations for road to Euclidean distance between the two groups of holdings where they were not separated by river estuaries. However, where pairs of holdings were separated by a river estuary (in this case the Severn estuary and Solway Firth) there was a significant difference. This is because road travel across estuaries is limited by the availability of crossing points, so road distance is generally greater when farms were separated by an estuary compared to instances in which they are not. In these instances road distance becomes a more appropriate measure of transmission risk. However, the analysis of Savill et al [9] considered all possible infection events within $10 \mathrm{~km}$, as opposed to having used transmission tracing data gathered through epidemiological investigations during the epidemic. Therefore the effects of road distance on transmission may have been masked by the nature of the IP pairings being used.

The current paper will extend the work of Savill et al [9] by investigating the potential for geographical features to act as conduits or barriers to infection during the period of local spread following the NMB. The analysis will be conducted at a more localised scale and at a far greater precision by analysing only known infection events and by looking at a greater range of geographical features. This will be accomplished by considering distance matched source-case-control groups where the source was believed to have infected the case but did not infect the control. The geographical features separating source-case and source-control pairings will then be compared.

\section{Results and discussion}

In the univariate analysis most predictor variables were not associated with differences between cases and controls at the $\mathrm{p}<0.2$ level, the exceptions were rivers and railways and road distance for which $\mathrm{p}=0.088,0.166$ and 0.098 respectively (Table 1 ). Numbers in the present groups for both rivers and railways were relatively small (61 and 27 respectively, Table 2 ). These features prevent transmission by forming linear barriers which inhibit movements of humans and animals across them, features described by Smith et al [10] as semipermeable barriers. Therefore, the rivers and railways categories were merged to form a single barriers variable and this was statistically significant at the $\mathrm{p}<0.05$ level ( $\mathrm{p}=0.018)$, with the number of cases separated by a barrier significantly lower than the number of controls (Table 3 ). The odds ratio of there being a barrier between source and case/control holding were 0.5 as high for cases than for controls (odds ratio $=0.507,95 \% \mathrm{CI}=$ $0.297,0.887)$.

In addition to controlling for Euclidean distance, animal numbers and indirectly (by capping the distance at $3 \mathrm{~km}$ ) for Disease Control Centre (DCC) in the group selection process these risk factors were further checked by inserting each of these terms into the model as a covariate. The insertion of these terms did not affect the significance of the barriers term, however the insertion of the Euclidean distance term did alter the p-value of the road distance term such that with the Euclidean distance term the pvalue of the road distance term is greater than 0.5 .

The presence of linear features in the form of rivers or railways is the only geographical influence on FMD transmission which could be detected using this methodology. The

Table I: Univariate generalised linear mixed model (binomial errors) analysis of predictor variables.

\begin{tabular}{lllll}
\hline Variable & Unit & odds ratio $(95 \%$ Cls $)$ & t-value & $\mathrm{P}$ \\
\hline Road distance & $\mathrm{km}$ & $\mathrm{I} .507(0.93,2.44)$ & $\mathrm{I} .66$ & 0.098 \\
Rivers & Absent & $\mathrm{I}$ & - & - \\
& Present & $0.594(0.33,1.08)$ & $-\mathrm{I} .72$ & 0.087 \\
Rail & Absent & $\mathrm{I}$ & - & - \\
& Present & $0.550(0.24,1.28)$ & $-\mathrm{I} .389$ & 0.166 \\
Forest & Absent & $\mathrm{I}$ & - & - \\
& Present & $\mathrm{I} .286(0.69,2.40)$ & 0.790 & $0.43 \mathrm{I}$ \\
Road & 0 & $\mathrm{I}$ & - & - \\
& $\mathrm{I}$ & $0.959(0.46,2.02)$ & $-\mathrm{I} .109$ & 0.913 \\
& $2 \& 3$ & $0.737(0.33,1.67)$ & -0.732 & 0.465 \\
Access & $\mathrm{I}$ & $\mathrm{I}$ & - & - \\
& 2 & $\mathrm{I} .17(0.72, \mathrm{I} .90)$ & 0.614 & 0.540 \\
& 3 & $0.95 \mathrm{I}(0.41,2.19)$ & -0.118 & 0.906 \\
Elevation change & $\sqrt{ } m$ & $0.965(0.92,1.01)$ & -1.448 & 0.149
\end{tabular}


Table 2: Number of instances of holdings being separated by rivers and railways.

\begin{tabular}{llll}
\hline & & Absent & Present \\
\hline River & Case & $94(83.2)$ & $16(14.2)$ \\
& Control & $141(74.6)$ & $45(23.8)$ \\
\hline \multirow{2}{*}{ Rail } & Case & $105(92.9)$ & $7(6.2)$ \\
& Control & $166(87.8)$ & $20(10.6)$ \\
\hline \multirow{2}{*}{ River \& Rail } & Case & $91(80.5)$ & $22(19.5)$ \\
& Control & $128(67.7)$ & $61(32.3)$ \\
\hline
\end{tabular}

Percentages based upon the row totals are in brackets.

principal mechanisms by which linear features reduce transmission would be by the prevention of the movements of animals, people and vehicles. Two farms separated by a small river may be less likely to have contacts, exchange personnel and have animals coming into contact compared to two farms separated by a fence or open farmland. A similar effect has been observed in rabies transmission, in which the presence of rivers were found to reduce the rate of progression of waves of rabies to one seventh of its speed before the river [10].

Although rivers and railways together were a statistically significant barrier to FMD transmission, roads were not a statistically significant barrier to transmission (Table 1). This supports previous studies [9] which demonstrated that even a major road such at the M6 motorway did not act as a barrier to FMD transmission. This may be a result of roads forming a more permeable barrier than rivers and railways. A set of 325 cases and 766 controls which had not been controlled for animal numbers was analysed using a generalised linear model with binomial error term to evaluate any differences in terms of numbers of animals on cases and controls (Table 4). Numbers of both cattle and sheep were statistically significantly lower on controls compared to cases irrespective of data source used (see methods). This supports previous findings that showed that IPs were larger farms [6] and also justified the criteria of selecting controls on animal numbers.

These detailed analyses of geographical influences on virus transmission were made possible by the highly detailed FMD datasets. The identification of source-case

Table 3: Multivariate generalised linear mixed model (binomial error term) of barriers as a risk factor for risk of FMD transmission.

\begin{tabular}{lllll}
\hline Predictor & Unit & odds ratio $(95 \% \mathrm{Cls})$ & t-value & $\mathrm{P}$-value \\
\hline Intercept & - & & -2.480 & 0.014 \\
Barriers & No & I & - & - \\
& Yes & $0.507(0.297,0.887)$ & -2.382 & 0.018
\end{tabular}

pairings was based upon the identification of putative sources of infection for IPs during the epidemic. These sources were identified through epidemiological investigations; data which have been used in previous studies $[6,11]$. However for many IPs the source could not be identified with certainty. Analysis of these data identified 386 inconsistencies in source identification based upon dates of infection and slaughter. Although these IPs were excluded, there is no simple way to detect any remaining errors. Since the epidemic it has been demonstrated that sources of infection can be established with a high degree of certainty using FMDV sequence data [12], however, these techniques have only been applied to 22 IPs from 2001 and therefore are of little value for this study.

\section{Conclusion}

Amongst the mainly geographical risk factors studied here, Euclidean distance and the number of animals on the susceptible holding appeared to be the most important determinant of risk of FMD transmission, a conclusion supported by previous analysis $[6,9]$. Beyond this it is difficult to draw further distinctions between holdings in terms of their relative susceptibilities based on these analyses. Despite the fact that some infectious contacts will be facilitated by the road network, road distance has again been shown not to be a more accurate predictor of transmission risk than simple Euclidean distance. However, this paper has demonstrated that these infectious contacts can be reduced by the presence of linear barriers in the form of rivers and railways but not roads, possibly because roads are too permeable to contacts across them. While the analysis was conducted on a small subset of 113 IPs (5.8\% of the IPs infected after the NMB), the size of the subset was the result of the rigorous group selection procedure. These IPs were compared to all IPs infected after the NMB to ensure that they were a representative sample and although almost significantly different in terms of species composition and spatial distribution the cases were a representative subset of all other IPs. In conclusion, the presence of rivers and railways should be incorporated into spatial models of FMD transmission to give more accurate estimates of transmission risk.

\section{Methods}

The study used a case-control methodology in which case and control selection was based upon their geographical relationship to a source IP. The process of matching controls to cases and sources is described below.

\section{Premises data}

Sources and cases were selected from the 2026 Infected Premises (IPs). Data on IPs are stored in the DEFRA Disease Control System (DCS) database [13]. This dataset included a coordinate for the main farm building, numbers of animals culled on the holding, estimated date of 
Table 4: Univariate generalised linear model (binomial error term) analysis of animal numbers by species on preliminary cases compared to controls.

\begin{tabular}{|c|c|c|c|c|c|c|}
\hline Species & Case data (n) & Control data (n) & Estimate & SE & $\chi^{2}$ & $P$ \\
\hline Cattle (100s) & DCS (325) & Census (766) & -0.561 & 0.061 & 98.59 & $<0.001$ \\
\hline Cattle (100s) & Census (218) & Census (766) & -0.626 & 0.080 & 63.34 & $<0.001$ \\
\hline Sheep (1000s) & DCS (325) & Census (766) & -0.998 & 0.153 & 46.7 & $<0.001$ \\
\hline Sheep (1000s) & Census (2|8) & Census (766) & -0.762 & 0.161 & 21.24 & $<0.001$ \\
\hline
\end{tabular}

infection, dates on which the IP was reported and slaughtered and the most likely source of infection for many IPs. The coordinates recorded in the DCS were the coordinates of the main farm building as this has been identified as the best location from which to georeference farm holdings [14]. However, in the DCS, instances in which the infected animals are more than $1 \mathrm{~km}$ from the main holding were georeferenced to the location of the affected stock [13].

IPs were considered as potential cases if they were:

1. Estimated to have been infected after the NMB. This is because before the NMB was imposed there were a greater range of mechanisms of spread of FMD operating.

2. The IP had a reliable source of infection identified. A source of infection was considered reliable if the daughter IPs' livestock was infected after the source IP was infected but before the source IP was slaughtered.

\section{The IP had a source of infection within $3 \mathrm{~km}$.}

Controls were selected from the 139,195 holdings registered on the June 2000 agricultural censuses of England, Scotland and Wales. There was no census conducted in 2001, so the June 2000 census was the most appropriate dataset for these analyses and has been used extensively in analysis of the 2001 FMD epidemic $[4,7,15]$. Data in the agricultural census includes a coordinate for the main farm building and animal numbers by species.

\section{A holding was included as a potential control if it:}

1. Had no off-fields. Holdings with off-fields were identified using the holding number of the parcel of land and the name of the owner (data not shown). The number of animals on the off-fields can not be known with certainty and therefore only holdings without off-fields were included in these analyses.

2. Was within $4 \mathrm{~km}$ of an IP. A distance of $4 \mathrm{~km}$ was used as this allowed a window either side of the $3 \mathrm{~km}$ definition of local spread.

\section{Identifying groups}

Potential controls were matched to a case-source pair based on the Euclidean distance from source to potential control $\left(d_{n}\right)$ and the distance from source to case $\left(d_{c}\right)$. Groups were matched where:

$$
-250 m<d_{n}-d_{c}<199.5 m
$$

Asymmetric bounds were used to equalise the area either side of $d_{c^{\prime}}$ thus ensuring that similar numbers of controls were selected on either side of $d_{c}$.

Controls which were culled at a later point in the epidemic were included if the animals on the premises were slaughtered more than 14 days after the source was slaughtered. This allows for the maximum incubation time $[16,17]$ removing the possibility that the control had been infected by the source. Furthermore, if the potential control was an IP it must have been infected at least 14 days after the source was slaughtered to allow for error in the estimated infection date of the potential control.

It has previously been shown [6] that animal numbers on the premises are a risk factor for susceptibility. Therefore groups were evaluated to look for differences between case and control(s) in terms of animal numbers (Figure 1). As a consequence of differences in the definition of a farm premises described above and the time of year at which the data were gathered, animal numbers on the agricultural census and DCS may have differed for an individual holding. Therefore, animal numbers on case and control(s) were compared using two methods depending upon data availability:

1. For the cases for which there is census data, the census numbers on the case were compared to the census numbers on the control.

2. Animal numbers from the DCS were compared to animal numbers on the census for all case-control pairs.

To ensure that the number of animals was controlled for, the numbers of animals on the control had to be similar to those on the case as defined by the following criteria: 

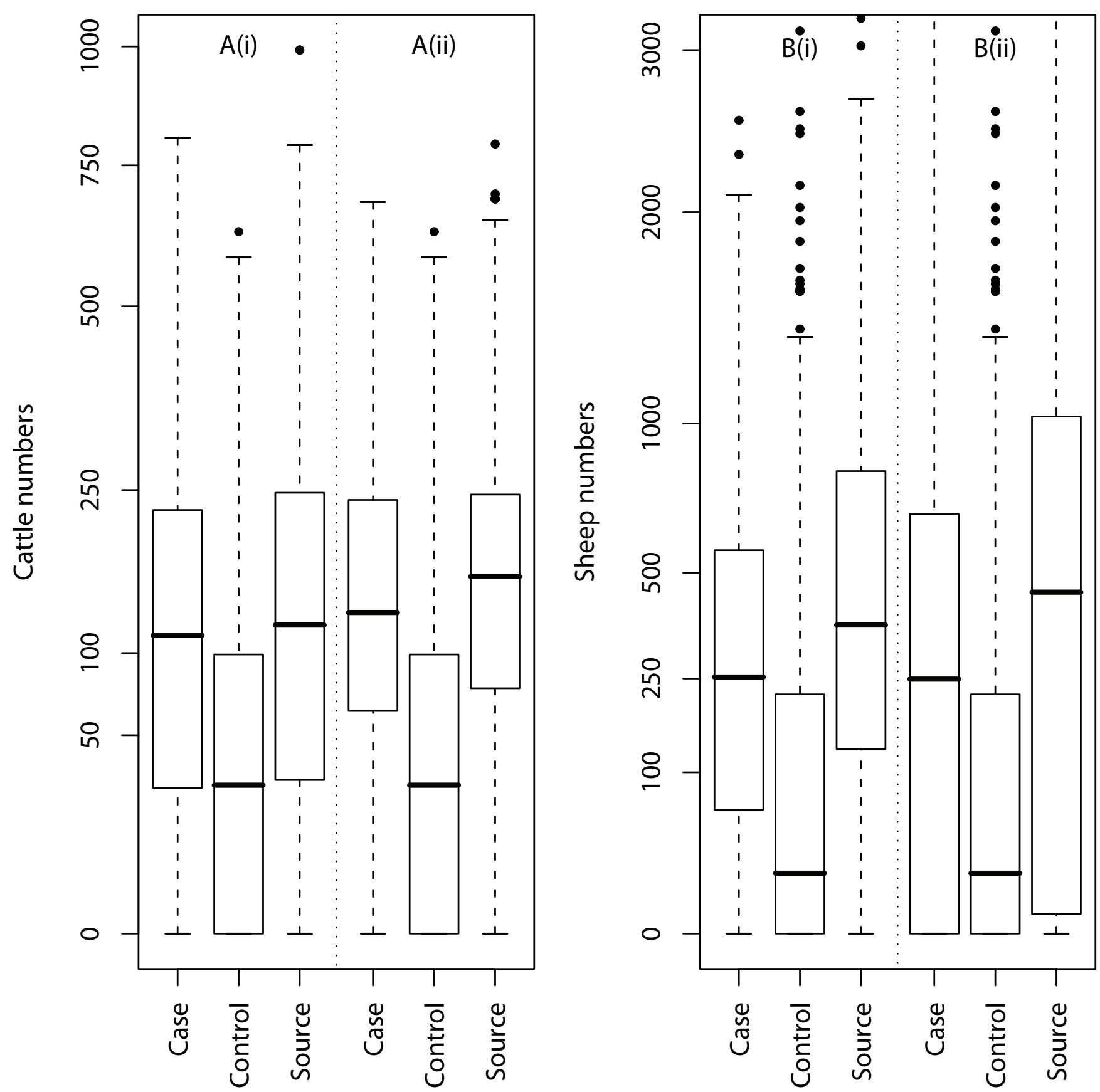

Figure I

Comparisons of numbers of cattle (A) and sheep (B) on cases, sources and controls broken down by census animal numbers (ii) and DCS animal numbers (i). Whiskers represent 1.5 times the standard deviation and the $y$-axes are square-root transformed.

1. The control had at least $70 \%$ of the numbers of cattle, sheep and pigs on the case.

2. The control had no more than 50 fewer cattle than the case and no more than 100 fewer sheep and pigs than the case.
3. The control must have held cattle if the case held cattle.

The latter criterion made allowances for relatively small holdings, for instance it allowed a case with 50 head of cattle to be paired with a control with 30 head. 
There were instances of a control being a control for 2 cases. In these instances the controls was assigned to just one case; if one of the cases had more than one control the control was removed from that group, otherwise one of the groups was selected at random. The resulting dataset comprised 113 groups which were composed of 113 cases and 188 controls. The selection criteria which generated these data are summarised as:

1. The control if culled was culled more than 14 days after the case.

2. The control if an IP was infected more than 14 days after the case.

3. Groups which meet the distance matching criteria described above.

4. Matching for animal numbers as described above.

5. Ensuring that a control was matched to only one case.

The 113 cases were checked for representativeness by comparing the cases to all other IPs infected after the NMB. The cases were not statistically significantly different from the IPs in terms of species composition described by whether the holding was cattle only, sheep only or mixed $\left(\chi_{2}^{2}=\right.$ $5.59 \mathrm{p}=0.061$ ), temporal distribution (KolmogorovSmirnov test based upon estimated dates of infection $\mathrm{p}=$ $0.126)$ and spatial distribution based upon Disease Control Centre (Fishers Exact Test $p=0.057$ ). Therefore the identified cases appeared to be a valid representation of the IP set.

\section{Predictors}

Road distance was calculated between two points by overlaying the data onto scanned Ordnance Survey 1:50,000 scale topographic maps supplied by the EDiNA Digimap service [18] and calculating the shortest distance along roads using the measure tool in ESRI ArcGIS 9. Intervening rivers and railways and forest were derived from the same maps in turn by taking a straight line between two points and evaluating intervening features by presence or absence of the features. Intervening roads were measured on the following scale:

$0=$ no intervening road.

$1=$ Minor road only.

$2=\mathrm{B}$, A road or motorway
Accessibility was derived from the locations of cases and controls on the maps on the following scale:

$1=$ Track or dead end road

2 = Beside a minor road

3 = Beside a main road.

Cumulative elevation change between two holdings was derived from an OS 1:50,000 Digital Elevation Model supplied by EDiNA [18] after tiles for the necessary regions were mosaiced in ArcGIS 9.0. Straight lines between the points were generated in ESRI ArcView 3.2 and cumulative elevation change along the lines calculated using the surface tools extension in ArcView 3.2 [19].

\section{Statistical analysis}

The outcome for each holding (whether it was a case or control) formed a binary outcome variable with the control category the reference level. The effect of having multiple distance matched controls for each case was handled by classifying each case and all its controls as a group. The group was added to the logistic regression model as a random effect to form a mixed effects logistic regression model in which variables were considered statistically significant when $\mathrm{p}<0.05$. This was implemented in the MASS Package [20] for the R statistical environment [21]. Interrelationships between univariate predictors which were significant at $\mathrm{p}<0.2$ were analysed in a multivariate model. Significance of the predictors was evaluated using the Wald statistic and the logits of continuous variables were inspected for linearity. The effectiveness of the selection process was checked by inserting Euclidean distance (source to case), animal numbers by species on the holding and DCC into the model. Any major change to the significance of predictor would suggest that a factor had not been adequately controlled for and could bias the results.

\section{Authors' contributions}

PRB drafted the manuscript. PRB, DJS, NJS and MEJW conceived the study. DJS helped with statistical analysis and with cleaning the data. All authors critically assessed the study and read and approved the final manuscript.

\section{Acknowledgements}

PRB is supported by a BBSRC studentship and MEJW by the Wellcome Trust. We thank Miles Thomas from the Central Science laboratory DEFRA, Sand Hutton, Yorkshire for his invaluable help with the data. We are grateful to three anonymous referees for their valuable comments on this paper.

\section{References}

I. Anderson I: Foot and Mouth Disease 200I: Lessons to be Learned Inquiry Report The Stationary Office: London; 2002.

2. Thompson D, Muriel P, Russell D, Osborne P, Bromley A, Rowland $M$, Creigh-Tyte S, Brown C: Economic costs of the foot and 
mouth disease outbreak in the United Kingdom in 200I. Rev Sci Tech 2002, 2 I(3):675-687.

3. Sørensen JH, Mackay DK, Jensen CO, Donaldson Al: An integrated model to predict the atmospheric spread of foot-and-mouth disease virus. Epidemiol Infect 2000, I 24(3):577-590.

4. Ferguson NM, Donnelly CA, Anderson RM: The foot-and-mouth epidemic in Great Britain: pattern of spread and impact of interventions. Science 200I, 292(55 I9): I I55-I I 60.

5. Ferguson NM, Donnelly CA, Anderson RM: Transmission intensity and impact of control policies on the foot and mouth epidemic in Great Britain. Nature 200 I, 4I3(6855):542-548.

6. Keeling MJ, Woolhouse ME, Shaw DJ, Matthews L, Chase-Topping M, Haydon DT, Cornell SJ, Kappey J, Wilesmith J, Grenfell BT: Dynamics of the 200I UK foot and mouth epidemic: stochastic dispersal in a heterogeneous landscape. Science 200I, 294(5543):813-817.

7. Keeling MJ, Woolhouse MEJ, May RM, Davies G, Grenfell BT: Modelling vaccination strategies against foot-and-mouth disease. Nature 2003, 421 (69 I9): I36- I42.

8. Tildesley M, Savill N, Shaw D, Deardon R, Brooks S, Woolhouse M, Grenfell B, Keeling M: Optimal reactive vaccination strategies for a foot-and-mouth outbreak in the UK. Nature 2006 , 440(7080):83-86.

9. Savill NJ, Shaw DJ, Deardon R, Tildesley MJ, Keeling MJ, Woolhouse MEJ, Brooks SP, Grenfell BT: Topographic determinants of foot and mouth disease transmission in the UK $200 \mathrm{I}$ epidemic. BMC Vet Res 2006, 2:3.

10. Smith D, Lucey B, Waller L, Childs J, Real L: Predicting the spatial dynamics of rabies epidemics on heterogeneous landscapes. Proc Natl Acad Sci USA 2002, 99(6):3668-3672.

II. Haydon DT, Chase-Topping M, Shaw DJ, Matthews L, Friar JK, Wilesmith J, Woolhouse MEj: The construction and analysis of epidemic trees with reference to the 2001 UK foot-and-mouth outbreak. Proc Biol Sci 2003, 270( I I I I): | 2 |-I27.

12. Cottam E, Haydon D, Paton D, Gloster J, Wilesmith J, Ferris N, Hutchings G, King D: Molecular epidemiology of the foot-andmouth disease virus outbreak in the United Kingdom in 200 I. J Virol 2006, 80(22): I I 274-I I 282.

13. Gibbens JC, Wilesmith JW: Temporal and geographical distribution of cases of foot-and-mouth disease during the early weeks of the 2001 epidemic in Great Britain. Vet Rec 2002, I5 I( I4):407-4I2

14. Durr PA, Froggatt AEA: How best to geo-reference farms? A case study from Cornwall, England. Prev Vet Med 2002, 56:5I-62.

15. Matthews L, Haydon DT, Shaw DJ, Chase-Topping ME, Keeling MJ, Woolhouse ME]: Neighbourhood control policies and the spread of infectious diseases. Proc Biol Sci 2003, 270(1525): 1659-I666.

16. Kitching RP: Clinical variation in foot and mouth disease: cattle. Rev Sci Tech 2002, 2 I(3):499-504

17. Kitching RP, Hughes GJ: Clinical variation in foot and mouth disease: sheep and goats. Rev Sci Tech 2002, 2 I(3):505-5I2.

18. EDiNA: Digimap Service. [http://www.edina.ac.uk]

19. Jenness J: Surface Tools (surf_tools.avx) extension for ArcView 3.x, v. I.6 Jenness Enterprises; 2005

20. Venables WN, Ripley BD: Modern Applied Statistics with S fourth edition. New York: Springer; 2002.

21. R Development Core Team: $R$ : A language and environment for statistical computing R Foundation for Statistical Computing, Vienna, Austria; 2004.
Publish with Bio Med Central and every scientist can read your work free of charge

"BioMed Central will be the most significant development for disseminating the results of biomedical research in our lifetime. "

Sir Paul Nurse, Cancer Research UK

Your research papers will be:

- available free of charge to the entire biomedical community

- peer reviewed and published immediately upon acceptance

- cited in PubMed and archived on PubMed Central

- yours - you keep the copyright
BioMedcentral 